\title{
Improvements of Doxorubicin-Induced Antitumor Activity and Adverse Reaction by Combined Citrulline
}

\author{
Michiko Miyashita and Yasuyuki Sadzuka* \\ Department of Advanced Pharmaceutics, School of Pharmacy, Iwate Medical University; 2-1-1 Nishitokuta, \\ Yahaba-cho, Shiwa-gun, Iwate 028-3694, Japan.. \\ Received October 16, 2013; accepted December 20, 2013
}

\begin{abstract}
Citrulline is an amino acid with antioxidant activity. In this study, effects of citrulline on the adverse effects of doxorubicin (DOX) and DOX-induced antitumor activity were examined. Citrulline significantly inhibited DOX-induced increases in lipid peroxide (LPO) in the heart as adverse reaction. Combined treatment with DOX and citrulline increased DOX levels in tumor cells and enhanced cytotoxicity in vitro by significantly increasing DOX uptake compared with DOX treatment alone. In simultaneous in vivo treatments, combination treatment with DOX and citrulline decreased tumor weight and increased DOX concentrations in tumors. Promotion of DOX uptake by citrulline enhanced the antitumor activity of DOX through the action of energy-independent and $\mathrm{Na}^{+}$-independent transporters. This effect of citrulline on DOX influx is identical to that of $S$-(4-nitrobenzyl)-6-thioinosine, promoting DOX influx through the equilibrative nucleoside transporter 1 . Therefore, it is anticipated that citrulline as a food component may enhance DOX efficacy.
\end{abstract}

Key words citrulline; doxorubicin; adverse reaction; antitumor activity; doxorubicin permeability

Currently, cancer therapies include surgery, radiation therapy, and chemotherapy, which is appropriate for hematological tumors and general metastases. Among cancer chemotherapies, alkylating agents, antimetabolites, plant alkaloids, antitumor antibiotics platinum compounds, and molecular targeting agents are used. Furthermore, because mechanisms of antitumor agents vary, combined therapies offer clinical potential to enhance antitumor activity and reduce adverse reactions. ${ }^{1-5)}$ In contrast, while some biochemical modulators without antitumor activity enhance the pharmacological properties of antitumor agents, these can improve the therapeutic indexes or ameliorate adverse reactions by antitumor agents. However, these therapies often enhance antitumor agent induced adverse reactions with the increase in antitumor activity. Hence, developments and discoveries of novel modulators that enhance antitumor activities and reduce adverse reactions to antitumor agents are required.

The anthracycline doxorubicin (DOX) is widely used to treat a variety of malignancies, despite the severity of associated adverse reactions, such as cardiotoxicity. Although many studies report enhancement of DOX antitumor activity in tumor cells by direct inhibition of DOX efflux, no agents or combinations have been found to increase the therapeutic index of DOX by expression of these efflux pumps in normal tissues. Previously, we reported improved DOX-induced antitumor activity using the food components caffeine, theanine, and cucurbitacins. ${ }^{6-15)}$ It appeared that these effects were mediated by increased DOX concentration in the tumors, which suppress DOX efflux from tumor cells. In contrast, linalool promoted DOX influx into tumor cells and enhanced its activity by acting on the $\mathrm{Na}^{+}$-dependent nucleoside transporter (CNT) 3. ${ }^{16)}$ Furthermore, decreases in DOX levels following combined therapy with these dietary modulators in normal tissues could reduce adverse reactions to DOX, leading to enhanced antitumor activity, reduced patient burden, and increased quality of life.

Citrulline is an amino acid found in watermelon that has

The authors declare no conflict of interest. been shown to suppress arteriosclerosis ${ }^{17,18)}$ and recovery from fatigue $^{19)}$ and ameliorate ischemic heart disease, ${ }^{20)}$ thereby offering potential as a novel health food. Moreover, citrulline acts as an antioxidant ${ }^{21)}$ and may reduce adverse reactions to DOX by inhibiting lipid peroxide (LPO) accumulation in the heart. However, this mechanism may decrease the antitumor activity of DOX because DOX acts by producing oxygen radicals. In this study, the effects of citrulline on cardiotoxicity and the antitumor activity of DOX were examined.

\section{MATERIALS AND METHODS}

Materials DOX, at $10 \mathrm{mg} /$ vial $\left(\operatorname{Adriacin}^{\circledR}\right)$, was purchased from Kyowa Hakko Kirin Co., Ltd. (Tokyo, Japan). Citrulline, sodium azide, and $S$-(4-nitrobenzyl)-6-thioinosine (NBMPR) were purchased from Wako Pure Chemical Industries, Ltd. (Tokyo, Japan). 2-Deoxy-D-glucose was purchased from Tokyo Chemical Industry Co., Ltd. (Tokyo, Japan). RPMI 1640 medium was obtained from Nissui Pharmaceutical Co., Ltd. (Tokyo, Japan). WST-8 was purchased from Dojindo Laboratories (Kumamoto, Japan). Drugs were dissolved in sterile isotonic saline. All other chemicals used in this study were of the highest purity available.

Animals Male $\mathrm{CDF}_{1}, \mathrm{DBA} / 2$, and $\mathrm{BDF}_{1}$ mice (5 weeks old, 20-25g) were obtained from Japan SLC, Inc. (Hamamatsu, Japan). Animals were housed in a room that was maintained at $25 \pm 1^{\circ} \mathrm{C}$ and $55 \pm 5 \%$ relative humidity and were allowed free access to regular chow pellets and water. Animal experiments were approved by the institutional animal care and use committee at Iwate Medical University.

Determination of LPO in Hearts and Livers of $\mathrm{CDF}_{1}$ Mice in Vivo DOX $(15 \mathrm{mg} / \mathrm{kg})$ was intraperitoneally injected into $\mathrm{CDF}_{1}$ mice. Citrulline (10 or $100 \mathrm{mg} / \mathrm{kg} / \mathrm{d}$ for $5 \mathrm{~d}$ ) was intraperitoneally injected daily starting from the day before DOX administration. Mice were killed by cervical dislocation on the day after the last citrulline injection (the 4th day after DOX administration), and their hearts and livers were immediately removed and weighed. Tissue samples were homogenized in 10 volumes (w/v) of $10 \mathrm{~mm}$ phosphate buffer $(\mathrm{pH}$ 
7.8). LPO concentrations in each sample were assayed using the thiobarbituric acid method. ${ }^{22)}$

Effect of Citrulline on DOX-Induced Cytotoxicity in P388 Leukemia Cells P388 leukemia cells $\left(1.0 \times 10^{6}\right.$ cells/ animal) were intraperitoneally transplanted into male DBA/2 mice. Ascites fluid was collected $7 \mathrm{~d}$ after transplantation. Leukemia cells were washed twice and then resuspended in RPMI 1640 medium containing 10\% fetal bovine serum.

P388 leukemia cell suspensions $\left(1.0 \times 10^{6}\right.$ cells $/ \mathrm{mL}$ medium $)$ were seeded into 96-well plates (Falcon) and incubated at $37^{\circ} \mathrm{C}$ for $24 \mathrm{~h}$. After incubation, DOX (90 or $900 \mathrm{~nm}$ ) was added to the cell suspension and incubated at $37^{\circ} \mathrm{C}$ for $48 \mathrm{~h}$ in the presence or absence of citrulline $(1.0,10$, or $100 \mu \mathrm{M})$. Subsequently, WST-8 $(10 \mu \mathrm{L})$ was added and the suspension was incubated at $37^{\circ} \mathrm{C}$ for $3 \mathrm{~h}$. Absorbance at $450 \mathrm{~nm}$ was determined, and the probability of cell survival was expressed as a percentage of that of untreated control cells. Experiments were repeated at least 3 times.

Effects of Citrulline on DOX Concentrations in P388 Leukemia Cells in Vitro To examine DOX influx into P388 leukemia cells, cells $\left(5.0 \times 10^{6}\right.$ cells $\left./ \mathrm{mL}\right)$ were incubated with $9.0 \mu \mathrm{M} \mathrm{DOX}$ at $37^{\circ} \mathrm{C}$ for $60 \mathrm{~min}$ in the presence or absence of citrulline $(0.1$ or $1.0 \mu \mathrm{M})$

To examine the effect of citrulline on DOX efflux from P388 leukemia cells, cells were preincubated with $9.0 \mu \mathrm{M}$ DOX at $37^{\circ} \mathrm{C}$ for $20 \mathrm{~min}$. After incubation, the medium was cooled on ice and then centrifuged at $150 \times \boldsymbol{g}$ for $3 \mathrm{~min}$. Cells were washed and then resuspended in fresh medium. The resulting cell suspension $\left(5.0 \times 10^{6}\right.$ cells $\left./ \mathrm{mL}\right)$ was incubated at $37^{\circ} \mathrm{C}$ for $30 \mathrm{~min}$ in the presence or absence of citrulline $(0.1$ or $1.0 \mu \mathrm{M})$.

In both systems, the cell suspension was cooled on ice after incubation and was then centrifuged at $150 \times \mathbf{g}$ for $3 \mathrm{~min}$. Cells were washed and resuspended in ice cold phosphate buffer $(10 \mathrm{~mm}, \mathrm{pH} 7.8)$. Cell suspensions were mixed for $30 \mathrm{~s}$ with $5.0 \mathrm{~mL}$ of chloroform-methanol $(4: 1, \mathrm{v} / \mathrm{v})$ and then centrifuged at $1200 \times \boldsymbol{g}$ for $15 \mathrm{~min}$. The concentration of DOX in the organic phase was determined using a fluorescence spectrophotometer (excitation wavelength, $470 \mathrm{~nm}$; emission wavelength, $580 \mathrm{~nm}){ }^{8,23)}$

Effect of Citrulline on DOX-Induced Antitumor Activity in Vivo P388 leukemia cells $\left(5.0 \times 10^{5}\right.$ cells/animal) were subcutaneously transplanted into the backs of $\mathrm{BDF}_{1}$ mice. DOX $(2.0 \mathrm{mg} / \mathrm{kg} / \mathrm{d})$ was intraperitoneally injected on days 3 , 5, 7, and 9 after inoculation. Citrulline $(20$ or $100 \mathrm{mg} / \mathrm{kg} / \mathrm{d})$ was intraperitoneally injected on days $4,6,8$, and 10 post inoculation (alternate treatment), or at $100 \mathrm{mg} / \mathrm{kg} / \mathrm{d} 3 \mathrm{~h}$ before each DOX administration (simultaneous treatment). The mice were sacrificed by cervical dislocation on day 11 post implantation, and solid tumors, hearts, livers, lungs, and kidneys were immediately removed and weighed. Tissue samples were homogenized in 10 volumes (w/v) of $10 \mathrm{~mm}$ phosphate buffer ( $\mathrm{pH}$ 7.8). Each suspension was mixed for $60 \mathrm{~s}$ with $5.0 \mathrm{~mL}$ of chloroform-methanol $(4: 1, \mathrm{v} / \mathrm{v})$ and then centrifuged at $1200 \times \boldsymbol{g}$ for $15 \mathrm{~min}$. DOX concentrations were determined as described above.

Effects of Citrulline on DOX Permeability. Effects of ATP Depletion on DOX Permeability To examine the effect of citrulline on DOX influx into P388 cells under ATP-depleted conditions, cells $\left(5.0 \times 10^{6}\right.$ cells $/ \mathrm{mL}$ medium $)$ were preincubated with sodium azide $(10 \mathrm{~mm})$ and 2-deoxy-Dglucose $(10 \mathrm{~mm})$ in RPMI medium at $37^{\circ} \mathrm{C}$ for $20 \mathrm{~min}$. After incubation, cells were incubated with $0.9 \mu \mathrm{M}$ DOX at $37^{\circ} \mathrm{C}$ for $10 \mathrm{~min}$ in the presence or absence of $1.0 \mu \mathrm{M}$ citrulline. After incubation, the cell suspension was examined as described above.

Effects of $\mathrm{Na}^{+}$on DOX Permeability To examine the effect of sodium ions on citrulline-induced changes in DOX influx in P388 leukemia cells, cells $\left(5.0 \times 10^{6}\right.$ cells $\left./ \mathrm{mL}\right)$ were suspended in Hanks' balanced salt solution (HBSS; pH 7.4) or choline-replaced HBSS. Cells were preincubated with sodium azide (10 mm) and 2-deoxy-D-glucose (10 mm) in HBSS, or choline-replaced $\mathrm{HBSS}$, at $37^{\circ} \mathrm{C}$ for $20 \mathrm{~min}$. After incubation, cells were incubated with $0.2 \mu \mathrm{M}$ DOX at $37^{\circ} \mathrm{C}$ for $3 \mathrm{~min}$ in the presence or absence of $1.0 \mu \mathrm{M}$ citrulline. After incubation, cell suspensions were examined as described above.

Effects of NBMPR on DOX Permeability To examine the effect of citrulline on DOX influx into P388 leukemia cells in the presence and absence of NBMPR in RPMI medium, cells $\left(5.0 \times 10^{6}\right.$ cells $/ \mathrm{mL}$ medium) were preincubated with sodium azide $(10 \mathrm{~mm})$ and 2-deoxy-D-glucose $(10 \mathrm{~mm})$ in the presence and absence of NBMPR $(10 \mu \mathrm{M})$ in RPMI medium at $37^{\circ} \mathrm{C}$ for $20 \mathrm{~min}$. After incubation, cells were incubated in medium containing $0.5 \mu \mathrm{M} \mathrm{DOX}$ at $37^{\circ} \mathrm{C}$ for $5 \mathrm{~min}$ in the presence or absence of $1.0 \mu \mathrm{M}$ citrulline. After incubation, cell suspensions were examined as described above.

Effects of NBMPR or Citrulline on DOX Permeability in the Absence of $\mathrm{Na}^{+}$To examine the effects of NBMPR or citrulline on DOX influx into P388 leukemia cells in choline-replaced HBSS, cells $\left(5.0 \times 10^{6}\right.$ cells $/ \mathrm{mL}$ HBSS $)$ were preincubated with sodium azide $(10 \mathrm{~mm})$ and 2-deoxy-D-glucose $(10 \mathrm{~mm})$ in $\mathrm{HBSS}$ at $37^{\circ} \mathrm{C}$ for $20 \mathrm{~min}$. After incubation, cells were incubated with $0.2 \mu \mathrm{M}$ DOX in $\mathrm{HBSS}$ at $37^{\circ} \mathrm{C}$ for $5 \mathrm{~min}$ in the presence or absence of NBMPR $(1.0,3.0,10,30$, or $100 \mu \mathrm{M})$ or citrulline $(0.01,0.1,1.0,10$, or $100 \mu \mathrm{M})$. After incubation, cell suspensions were examined as described above.

Statistical Analysis Statistical analysis was performed using Student's $t$-test and ANOVA. These statistical analyses were performed using Stat View 5.0 statistical software (ASA Institute Inc., Cary, NC, U.S.A.).

\section{RESULTS}

Effects of Citrulline on DOX-Induced Changes in LPO Levels in Vivo The effects of citrulline on DOX-induced changes in LPO levels in the heart and liver are shown in Fig. 1. LPO concentrations were significantly increased by 1.3 -fold in heart after DOX treatment $(4.29 \pm 0.45 \mathrm{nmol} / \mathrm{mg}$ protein, $p<0.01)$ compared with that in control heart $(3.43 \pm 0.15 \mathrm{nmol} /$ mg protein; Fig. 1A). In contrast, citrulline $(100 \mathrm{mg} / \mathrm{kg})$ inhibited DOX-induced increases in LPO levels $(p<0.05)$. After combined citrulline and DOX treatment, LPO levels in the liver also tended to decrease (Fig. 1B).

Effect of Citrulline on DOX-Induced Cytotoxicity in P388 Leukemia Cells The cytotoxic effects of DOX in the presence of citrulline in P388 leukemia cells are shown in Fig. 2. Single treatments with DOX $(900 \mathrm{~nm})$ induced cytotoxicity in a concentration dependent manner, with survival ratios of $67 \%(p<0.05)$. Survival ratios of tumor cells after single treatments with citrulline $(<1000 \mu \mathrm{M})$ did not differ from those of the control group (data not shown). The cytotoxicity of DOX at $90 \mathrm{~nm}$ (no effect concentration) increased with increase in citrulline concentration. At $10 \mu \mathrm{M}$ citrulline the effect of DOX 


\section{(A) Heart}

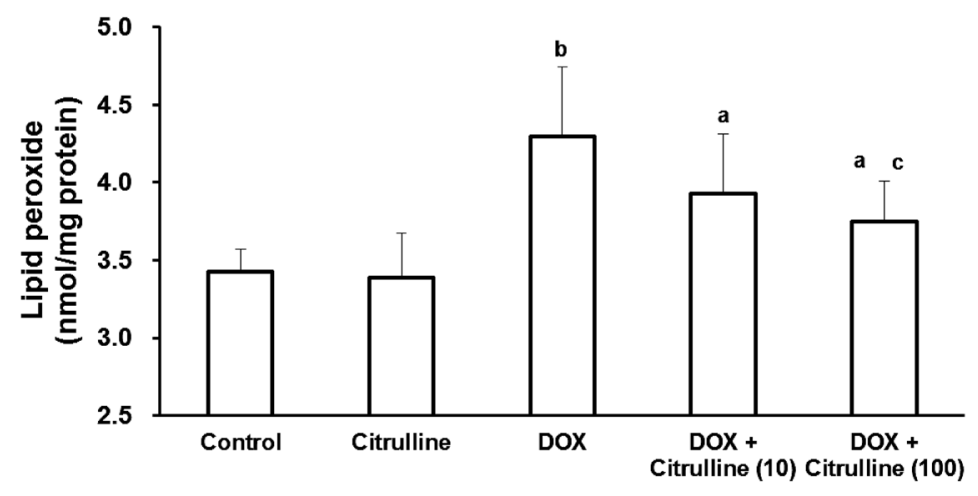

(B) Liver

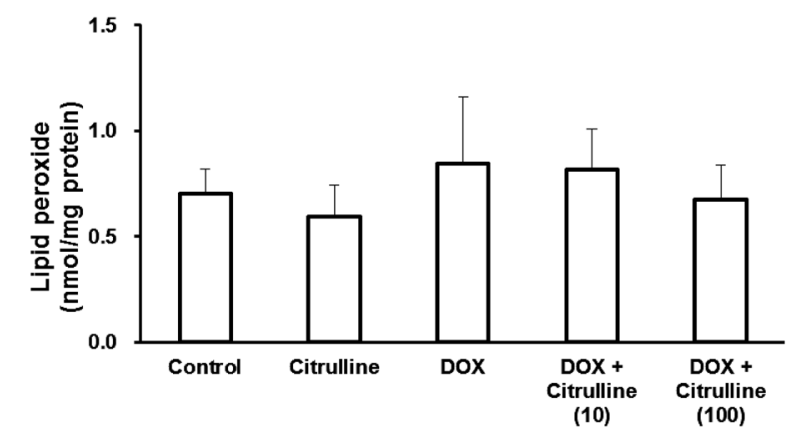

Fig. 1. Effect of Citrulline on DOX-Induced Changes in Lipid Peroxide Levels in the Hearts (A) and Livers (B) of Mice

Data are presented as the mean \pm S.D. $(n=5-6)$. Significant differences from the control group are indicated by (a) $p<0.05$ and (b) $p<0.01$. Significant difference from DOX alone treated mice is indicated by (c) $p<0.05$. Citrulline (10), $10 \mathrm{mg} / \mathrm{kg}$ citrulline; Citrulline (100), $100 \mathrm{mg} / \mathrm{kg}$ citrulline.

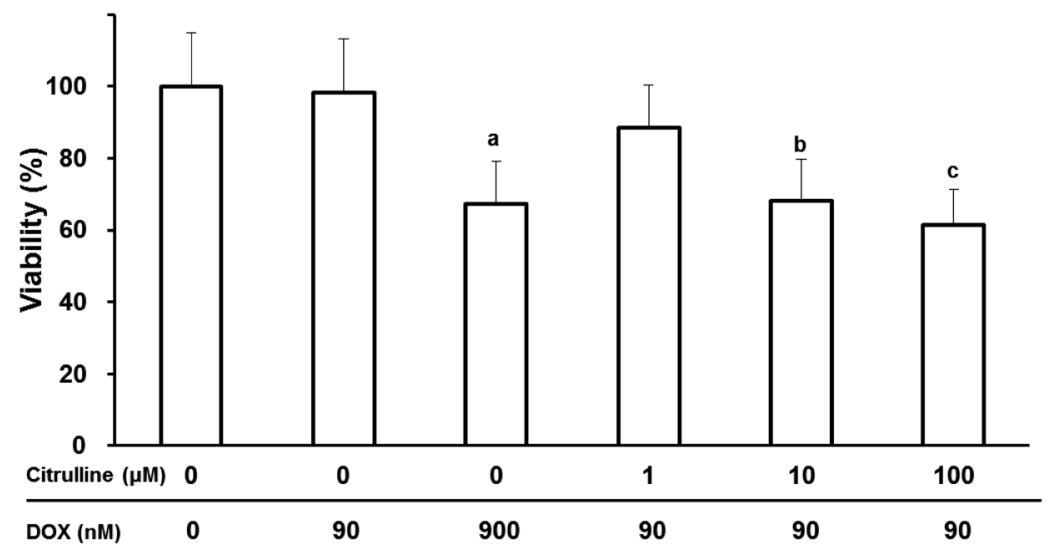

Fig. 2. Cytotoxic Effects of DOX Combined with Citrulline in P388 Leukemia Cells

Data are expressed as a percentage of untreated control cell viability, and are presented as the mean \pm S.D. $(n=5-8)$. Significant difference from control cells is indicated by (a) $p<0.01$. Significant differences from $90 \mathrm{~nm}$ DOX-treated cells are indicated by (b) $p<0.01$ and (c) $p<0.001$.

at its $\mathrm{IC}_{50}(0.73 \mu \mathrm{M})$ was increased to that of DOX at 2.7 -fold this concentration $(1.93 \mu \mathrm{M})$.

Effect of Citrulline on DOX Concentrations in P388 Leukemia Cells in Vitro The effects of citrulline on DOX influx and efflux in P388 leukemia cells are shown in Fig. 3. Citrulline promoted DOX influx into tumor cells in a concentration dependent manner with a significant 1.2-fold increase in intracellular DOX concentrations after co-treatment with citrulline for $60 \mathrm{~min}$. In contrast, citrulline had no effect on
DOX efflux.

Effect of Citrulline on DOX-Induced Antitumor Activity in Vivo The effects of citrulline on DOX-induced antitumor activity in P388 leukemia-bearing mice were examined. In alternate treatments (Fig. 4), tumor weights did not change after combination treatment with citrulline $(100,20 \mathrm{mg} / \mathrm{kg})$ and DOX $(0.52 \pm 0.04,0.53 \pm 0.12 \mathrm{~g}$, respectively) compared with the DOX alone treated group $(0.53 \pm 0.11 \mathrm{~g})$. In simultaneous treatments (Fig. 5), tumor weights in DOX alone treated mice 
$(0.72 \pm 0.23 \mathrm{~g})$ were decreased to $71 \%$ of the control $(1.02 \pm$ $0.16 \mathrm{~g})$, whereas in combination with $100 \mathrm{mg} / \mathrm{kg}$ citrulline, DOX decreased tumor weights to $52 \%(0.53 \pm 0.09 \mathrm{~g}, p<0.001$; Fig. 5A). DOX concentrations in tumors of citrulline cotreated animals increased by 2.8 -fold $(p<0.05)$ compared with those in the DOX alone treated group, whereas co-treatment with citrulline did not cause increased DOX concentrations in normal tissues (Fig. 5B).

Effects of Citrulline on DOX Permeability The effect of ATP depletion on DOX influx into P388 leukemia cells is shown in Fig. 6A. DOX influx into tumor cells after cotreatment with citrulline for $6 \mathrm{~min}$ significantly increased by

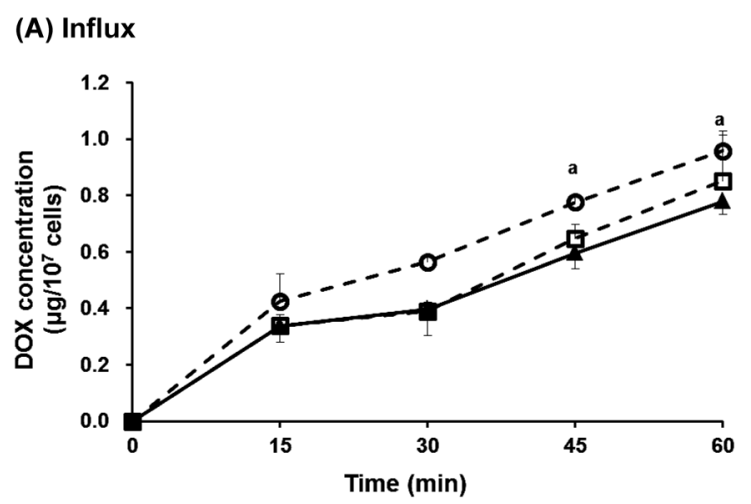

(B) Efflux

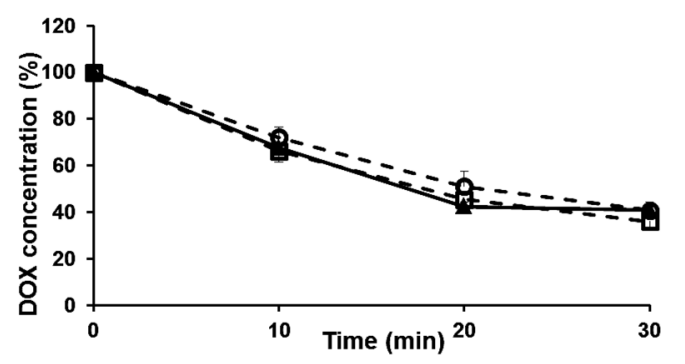

Fig. 3. Effect of Citrulline on DOX Influx (A) and Efflux (B) in P388 Leukemia Cells

Data are presented as the mean \pm S.D. $(n=3-4)$. Significant difference from DOX alone treated cells is indicated by (a) $p<0.01$. $\mathbf{\Delta}$, DOX; $\square$, DOX $+0.1 \mu \mathrm{M}$ citrulline; $\mathrm{DOX}+1 \mu \mathrm{M}$ citrulline.
$57 \%(p<0.05)$ compared with that in DOX alone treated cells, indicating that ATP depletion did not affect the promotion of DOX influx by citrulline.

The effects of $\mathrm{Na}^{+}$on the initial uptake rates of DOX into P388 leukemia cells are shown in Fig. 6B. Co-treatment with citrulline significantly promoted DOX influx in the presence and absence of $\mathrm{Na}^{+}(p<0.01)$, indicating that citrullineenhanced DOX uptake is independent of $\mathrm{Na}^{+}$.

The effects of citrulline and NBMPR on the uptake of DOX into P388 leukemia cells were examined. In the absence of NBMPR, DOX uptake was significantly increased by 1.5 -fold $(p<0.05)$ in the presence of citrulline. However, this enhance-

\section{(A) Tumor weight}

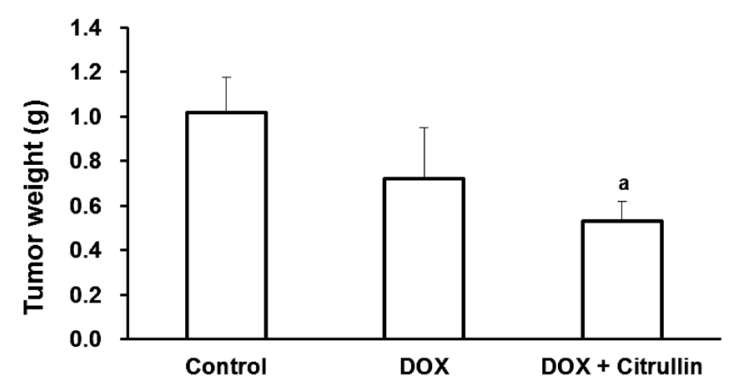

(B) DOX concentration

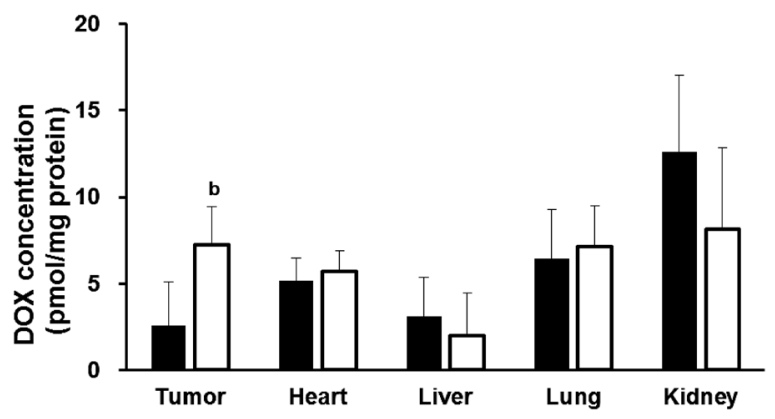

Fig. 5. Effect of Citrulline on Tumor Weights (A) and Cellular DOX Concentrations (B) in Simultaneously Treated P388 Leukemia Bearing Mice

Data are presented as the mean \pm S.D. $(n=4-7)$. Significant difference from the control group is indicated by (a) $p<0.001$. Significant difference from the DOX alone group is indicated by (b) $p<0.05$; Citrulline, $100 \mathrm{mg} / \mathrm{kg} / \mathrm{d}$ citrulline; $\mathbf{\square}$, DOX; $\square$, DOX+citrulline.

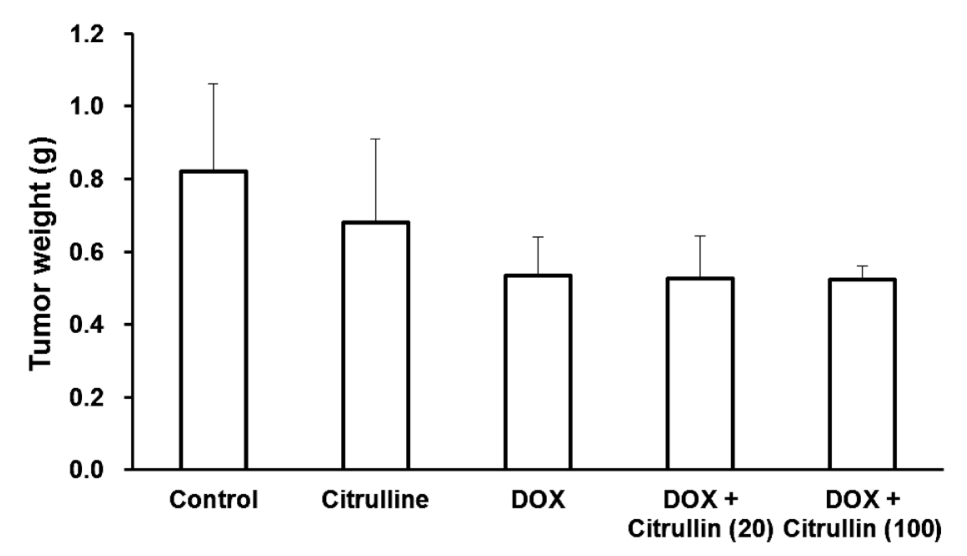

Fig. 4. Effect of Alternate DOX and Citrulline Treatment on DOX-Induced Changes in Tumor Weight 


\section{(A) ATP depletion}

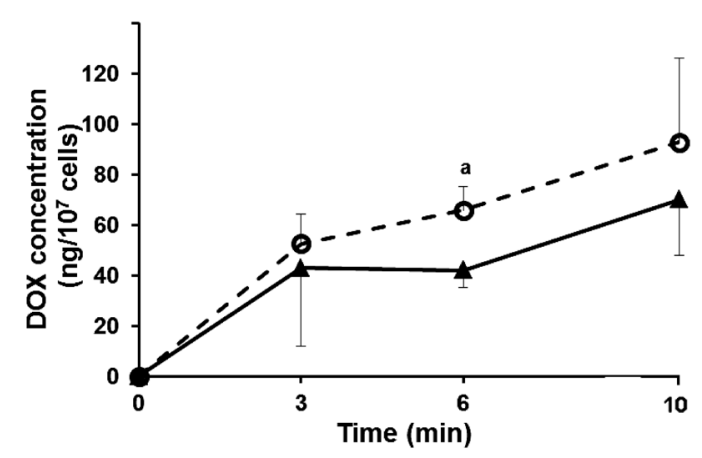

(B) $\mathrm{Na}^{+}$

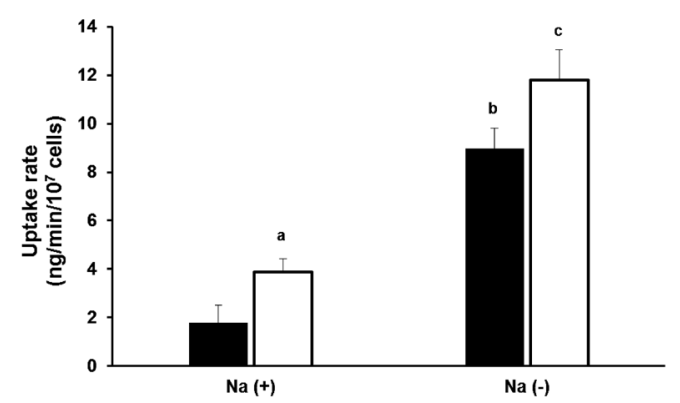

Fig. 6. Effect of ATP Depletion (A) and $\mathrm{Na}^{+}$(B) on DOX Concentrations in P388 Leukemia Cells

Data are presented as the mean \pm S.D. $(n=3)$. (A) P388 cells were incubated with $0.9 \mu \mathrm{M}$ DOX in the presence or absence of $1 \mu \mathrm{M}$ citrulline. Significant difference from the DOX alone group is indicated by (a) $p<0.05$. (B) P388 cells were incubated with $0.2 \mu \mathrm{M}$ DOX in the presence or absence of $1 \mu \mathrm{M}$ citrulline. Significant differences from the DOX alone group in the presence of $\mathrm{Na}^{+}$are indicated by (a) $p<0.01$ and (b) $p<0.001$. Significant difference from the DOX alone group in the absence of $\mathrm{Na}^{+}$is indicated by (c) $p<0.01$. (A) $\mathbf{\Delta}$, DOX; $\mathrm{O}, \mathrm{DOX}+$ citrulline; (B) DOX; $\square$, DOX+citrulline.

ment of DOX uptake was disappeared in the presence of NBMPR (data not shown), indicating that citrulline-enhanced DOX uptake was inhibited by NBMPR.

The effects of citrulline and NBMPR on DOX uptake ratios in the absence of $\mathrm{Na}^{+}$are shown in Fig. 7. DOX uptake was significantly increased in the presence of citrulline at $0.01-1 \mu \mathrm{M}$, but was decreased at $10 \mu \mathrm{M}$ citrulline (Fig. 7A). Furthermore, DOX uptake was also increased in the presence of NBMPR at $1-30 \mu \mathrm{m}$ whereas decreased at $100 \mu \mathrm{M}$ NBMPR (Fig. 7B). Both citrulline and NBMPR promoted DOX influx at low concentrations, but inhibited DOX influx at high concentrations in the absence of $\mathrm{Na}^{+}$.

\section{DISCUSSION}

Among various physiological activities in health foods, the amino acid citrulline may be recognized as a novel dietary antioxidant. ${ }^{21)}$ In this study, we showed that citrulline acts as a novel modulator of DOX efficacy that reduces the adverse reactions by DOX, and examined the effects of citrulline on DOX-induced antitumor activity.

It has reported that severe cardiotoxicity of DOX is caused by LPO accumulation in the heart. ${ }^{24,25)}$ Thus, we examined the effects of citrulline using LPO as an indicator of DOX cardiotoxicity, and observed significant inhibition of DOX-induced LPO accumulation in the heart. It is suggested that these effects were related to antioxidant activities, involving scav-

\section{(A) Citrulline}

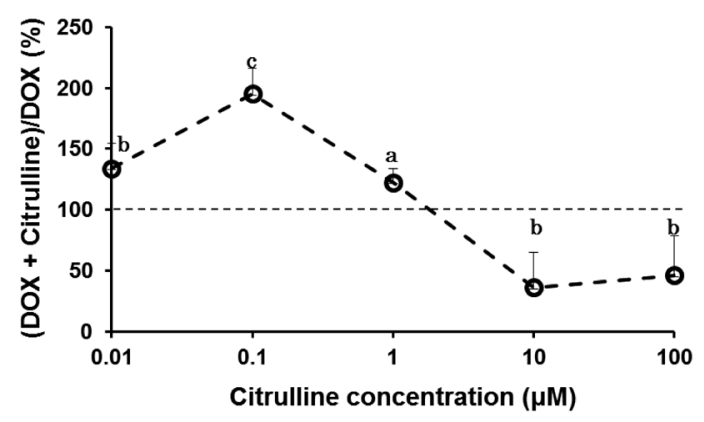

(B) NBMPR

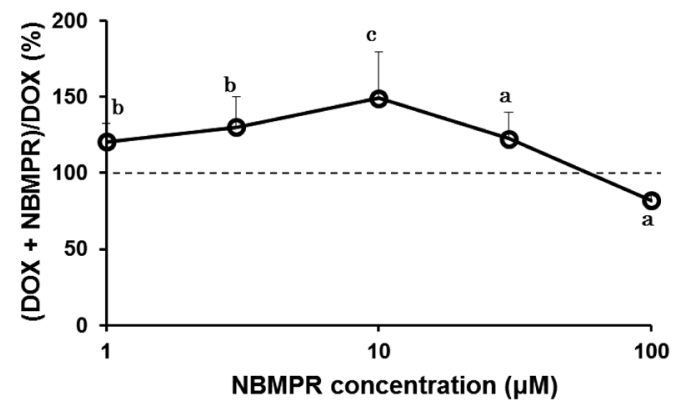

Fig. 7. Effects of Citrulline (A) and NBMPR (B) on DOX Uptake Ratios in the Absence of $\mathrm{Na}^{+}$

$100 \%$ : DOX level in DOX alone group. Each point represents the mean \pm S.D. $(n=3-6)$. P388 cells were incubated with $0.2 \mu \mathrm{M}$ DOX in the presence or absence of citrulline or NBMPR. Significant differences from the DOX alone group are indicated by (a) $p<0.05$, (b) $p<0.01$ and (c) $p<0.001$.

enging of hydroxyl radicals by citrulline. ${ }^{21)}$ Therefore, citrulline was expected to reduce DOX cardiotoxicity by inhibiting LPO accumulation in the heart.

However, inhibition of DOX-induced increases in LPO levels may prevent the antitumor activity of DOX. Hence, the cytotoxic effects of DOX were examined in the presence and absence of citrulline in vitro to clarify the effects of citrulline on DOX-induced antitumor activity. Combined treatment with DOX and citrulline increased DOX cytotoxicity depending on the concentration of citrulline, indicating that citrulline may enhance the antitumor activity of DOX rather than decreasing it.

To clarify the mechanisms by which citrulline increases the cytotoxicity of DOX, the effects of citrulline on DOX influx and efflux were examined in P388 leukemia cells. Although citrulline had no effect on DOX efflux, it significantly enhanced DOX influx, suggesting that citrulline may act by enhancing intracellular DOX concentrations in tumor cells.

To confirm the in vitro observation that citrulline enhanced DOX cytotoxicity by increasing DOX concentrations in tumor cells, the effects of citrulline on DOX-induced antitumor activity in P388 leukemia-bearing mice were examined in vivo. In previous study, combined treatment with DOX and linalool $(0.1 \mu \mathrm{M})$ significantly increased DOX cytotoxicity in vitro and DOX combined with linalool $(1.0 \mathrm{mg} / \mathrm{kg} / \mathrm{d})$ enhanced the antitumor activity in vivo. ${ }^{16)}$ In this study, combined treatment with DOX and $10 \mu \mathrm{M}$ citrulline significantly increased DOX cytotoxicity in vitro. Therefore, citrulline was administered at 
$100 \mathrm{mg} / \mathrm{kg} / \mathrm{d}$ in vivo. After alternate treatments, in which DOX and citrulline were administered separately at $24 \mathrm{~h}$ intervals, no changes in tumor weight were observed in comparison with DOX alone treated mice. However, in simultaneous treatments, in which citrulline was administered $3 \mathrm{~h}$ before DOX, tumor weights decreased compared with those treated with DOX alone. This result indicates that citrulline must be present in the tumor at the time of DOX treatment to enhance DOX uptake into cells. Thus, in the alternating treatment regimen, there may be little appropriately distributed citrulline in the tumor at the time of DOX treatment. On the other hand, simultaneous treatment resulted in distribution of citrulline in the tumor, which promoted influx and enhanced antitumor activity of DOX. Interestingly, DOX concentrations after combined citrulline and DOX treatment were not increased in normal tissues, thus it is speculated that citrulline promoted DOX influx through the action of tumor-specific transporters. Furthermore, citrulline may reduce adverse reactions to DOX by decreasing LPO levels in the heart as described above. Hence, combination therapy with citrulline may enhance the antitumor activity of DOX by reducing associated adverse reactions.

To further clarify the mechanisms by which citrulline enhances the antitumor activity of DOX, the effect of citrulline on DOX influx was examined in detail. Under ATP-depleted conditions that arrest active efflux of DOX, citrulline was shown to significantly promote DOX influx, indicating that citrulline promoted DOX influx via an ATP- and energy-independent system. Subsequently, the dependence of citrullineenhanced DOX permeability on $\mathrm{Na}^{+}$was examined in the absence of $\mathrm{Na}^{+}$. In these experiments, $\mathrm{Na}^{+}$had no effect on DOX influx in the presence of citrulline. Taken together, these data indicate citrulline promoted DOX influx was mediated by energy- and $\mathrm{Na}^{+}$-independent DOX transporter.

Members of the nucleoside transporter family, such as CNT and equilibrative nucleoside transporters (ENT), are energy-independent, ${ }^{26)}$ and are reported that the transporters appear in cancer cells. ${ }^{27)}$ While CNT transports DOX in an $\mathrm{Na}^{+}$-dependent manner, ENT is $\mathrm{Na}^{+}$-independent. ${ }^{27)}$ Because citrulline appears to enhance DOX influx via an energy- and $\mathrm{Na}^{+}$-independent transporter, we examined the effects of the ENT1 inhibitor NBMPR on DOX uptake in the presence of citrulline. In these experiments, the effect of citrulline on DOX uptake was inhibited in the presence of NBMPR, speculating that citrulline acts via ENT1. In the absence of $\mathrm{Na}^{+}$, low concentrations of NBMPR promoted DOX influx, whereas at high concentrations it inhibited DOX influx. Interestingly, citrulline showed similar behavior to NBMPR, indicating similar modes of action, presumably involving ENT1.

\section{CONCLUSION}

Citrulline ameliorates adverse reactions of DOX by inhibiting LPO accumulation in the heart, and by increasing DOX concentrations in tumor cells by enhancing the activity of DOX influx transporters, and therefore increased antitumor activity. Thus, we anticipate the recognition of citrulline as a food component that modulates DOX efficacy.

Acknowledgment The study was supported by a Grantin-Aid (Medical Innovation by Advanced Science and Tech- nology Project) for Scientific Research from the Ministry of Education, Culture, Sports, Science and Technology of Japan.

\section{REFERENCES}

1) Budd GT, Fleming TR, Bukowski RM, McCracken JD, Rivkin SE, O’Bryan RM, Balcerzak SP, Macdonald JS. 5-Fluorouracil and folinic acid in the treatment of metastatic colorectal cancer: a randomized comparison. A Southwest Oncology Group Study. J. Clin. Oncol., 5, 272-277 (1987).

2) Itamochi $H$, Oishi $T$, Shimada $M$, Sato S, Uegaki K, Naniwa J, Sato S, Nonaka M, Terakawa N, Kigawa J, Harada T. Inhibiting the mTOR pathway synergistically enhances cytotoxicity in ovarian cancer cells induced by etoposide through upregulation of c-Jun. Clin. Cancer Res., 17, 4742-4750 (2011).

3) Kubota T. The role of S-1 in the treatment of gastric cancer. Br. J. Cancer, 98, 1301-1304 (2008).

4) Ozols RF, Bundy BN, Greer BE, Fowler JM, Clarke-Pearson D, Burger RA, Mannel RS, DeGeest K, Hartenbach EM, Baergen R, Gynecologic Oncology Group. Phase III trial of carboplatin and paclitaxel compared with cisplatin and paclitaxel in patients with optimally resected stage III ovarian cancer: a Gynecologic Oncology Group Study. J. Clin. Oncol., 21, 3194-3200 (2003).

5) Vasey PA, Jayson GC, Gordon A, Gabra H, Coleman R, Atkinson R, Parkin D, Paul J, Hay A, Kaye SB, Scottish Gynaecological Cancer Trials Group. Phase III randomized trial of docetaxelcarboplatin versus paclitaxel-carboplatin as first-line chemotherapy for ovarian carcinoma. J. Natl. Cancer Inst., 96, 1682-1691 (2004).

6) Sadzuka Y, Mochizuki E, Iwazaki A, Hirota S, Takino Y. Caffeine enhances adriamycin antitumor activity in Ehrlich ascites carcinoma-bearing mice. Biol. Pharm. Bull., 18, 159-161 (1995).

7) Sadzuka Y, Mochizuki E, Takino Y. Mechanism of caffeine modulation of the antitumor activity of adriamycin. Toxicol. Lett., 75, 39-49 (1995).

8) Sadzuka Y, Sugiyama T, Miyagishima A, Nozawa Y, Hirota S. The effects of theanine, as a novel biochemical modulator, on the antitumor activity of adriamycin. Cancer Lett., 105, 203-209 (1996).

9) Sadzuka Y, Hatakeyama H, Daimon T, Sonobe T. Screening of biochemical modulator by tumor cell permeability of doxorubicin. Int. J. Pharm., 354, 63-69 (2008).

10) Sadzuka Y, Matsuura M, Sonobe T. The effect of taurine, a novel biochemical modulator, on the antitumor activity of doxorubicin. Biol. Pharm. Bull., 32, 1584-1587 (2009).

11) Sadzuka $Y$, Hatakeyama $H$, Sonobe $T$. Enhancement of doxorubicin concentration in the M5076 ovarian sarcoma cells by cucurbitacin E co-treatment. Int. J. Pharm., 383, 186-191 (2010).

12) Sadzuka Y, Fujiki S, Itai S. Enhancement of doxorubicin-induced antitumor activity and reduction of adverse reactions by cucurbitacin I. Food Res. Intern., 47, 64-69 (2012).

13) Sadzuka Y, Nagamine M, Toyooka T, Ibuki Y, Sonobe T. Beneficial effects of curcumin on antitumor activity and adverse reactions of doxorubicin. Int. J. Pharm., 432, 42-49 (2012).

14) Sadzuka Y, Sonobe T. Anserine induced advantage effects on the antitumor activity of doxorubicin. Food Chem. Toxicol., 45, 985989 (2007).

15) Sugiyama $T$, Sadzuka $Y$, Tanaka K, Sonobe T. Inhibition of glutamate transporter by theanine enhances the therapeutic efficacy of doxorubicin. Toxicol. Lett., 121, 89-96 (2001).

16) Miyashita M, Sadzuka Y. Effect of linalool as a component of Humulus lupulus on doxorubicin-induced antitumor activity. Food Chem. Toxicol., 53, 174-179 (2013).

17) Hayashi T, Juliet PA, Matsui-Hirai H, Miyazaki A, Fukatsu A, Funami J, Iguchi A, Ignarro LJ. 1-Citrulline and 1-arginine supplementation retards the progression of high-cholesterol-diet-induced atherosclerosis in rabbits. Proc. Natl. Acad. Sci. U.S.A., 102, 13681-13686 (2005). 
18) Ochiai M, Hayashi $T$, Morita $M$, Ina $K$, Maeda $M$, Watanabe $F$, Morishita K. Short-term effects of L-citrulline supplementation on arterial stiffness in middle-aged men. Int. J. Cardiol., 155, 257-261 (2012).

19) Takeda K, Machida M, Kohara A, Omi N, Takemasa T. Effects of citrulline supplementation on fatigue and exercise performance in mice. J. Nutr. Sci. Vitaminol., 57, 246-250 (2011).

20) Romero MJ, Platt DH, Caldwell RB, Caldwell RW. Therapeutic use of citrulline in cardiovascular disease. Cardiovasc. Drug Rev., 24, 275-290 (2006).

21) Akashi K, Miyake C, Yokota A. Citrulline, a novel compatible solute in drought-tolerant wild watermelon leaves, is an efficient hydroxyl radical scavenger. FEBS Lett., 508, 438-442 (2001).

22) Tanizawa H, Sazuka Y, Takino Y. Micro-determination of lipoperoxide in the mouse myocardium by thiobarbituric acid fluorophotometry. Chem. Pharm. Bull., 29, 2910-2914 (1981).

23) Sugiyama T, Sadzuka Y. Enhancing effects of green tea components on the antitumor activity of adriamycin against M5076 ovarian sarcoma. Cancer Lett., 133, 19-26 (1998).

24) Sazuka Y, Yoshikawa K, Tanizawa H, Takino Y. Effect of doxorubicin on lipid peroxide levels in tissues of mice. Jpn. J. Cancer Res., 78, 1281-1286 (1987).

25) Benchekroun MN, Pourquier P, Schott B, Robert J. Doxorubicin -induced lipid peroxidation and glutathione peroxidase activity in tumor cell lines selected for resistance to doxorubicin. Eur. J. Biochem., 211, 141-146 (1993).

26) Baldwin SA, Beal PR, Yao SY, King AE, Cass CE, Young JD. The equilibrative nucleoside transporter family, SLC29. Pflugers Arch., 447, 735-743 (2004).

27) Nagasawa K, Fumihara T, Ohnishi N, Yokoyama T. Contribution of the nucleoside transport system to doxorubicin transport in HL60 cells but not in mononuclear cells. Jpn. J. Cancer Res., 90, 781-787 (1999). 